\title{
Effects of silver-graphene oxide on seed germination and early growth of crop species
}

\author{
Min-Ji Kim ${ }^{1}$, Woong Kim ${ }^{1}$, Haegeun Chung ${ }^{\text {Corresp. } 2}$ \\ ${ }^{1}$ Department of Materials Science and Engineering, Korea University, Seoul, Republic of Korea \\ 2 Department of Environmental Engineering, Konkuk University, Seoul, Republic of Korea \\ Corresponding Author: Haegeun Chung \\ Email address: hchung@konkuk.ac.kr
}

Due to its excellent material properties, silver-graphene oxide (Ag-GO) is being studied for diverse applications, such as antimicrobial agents, catalysts, and absorbents. Such use of Ag-GO may lead to its release into terrestrial ecosystems, but little is known about the impact of Ag-GO on plants. In the present study, we determined the effects of Ag-GO on seed germination and early growth of crop species by analyzing the germination rate, growth of roots and shoots, hydrogen peroxide $\left(\mathrm{H}_{2} \mathrm{O}_{2}\right)$ accumulation, and the uptake of $\mathrm{Ag}$ in alfalfa, radish, and cucumber treated with 0.2 to $1.6 \mathrm{mg} \mathrm{mL}^{-1}$ of $\mathrm{Ag}-\mathrm{GO}$. Ag-GO treatment increased the shoot growth of radish at 0.2 to $1.6 \mathrm{mg} \mathrm{mL}^{-1}$ but decreased that of cucumber at $0.8 \mathrm{mg} \mathrm{mL}^{-1}$. In addition, Ag-GO enhanced the root elongation of radish at $0.2 \mathrm{mg} \mathrm{mL}^{-1}$ but inhibited that of alfalfa at $0.2,0.8$, and $1.6 \mathrm{mg} \mathrm{mL}^{-1}$. Ag-GO treatment induced $\mathrm{H}_{2} \mathrm{O}_{2}$ production in alfalfa, radish, and cucumber in a concentration-dependent manner. Larger amounts of $\mathrm{Ag}$ accumulated in the seedlings as the concentration of $\mathrm{Ag}-\mathrm{GO}$ increased, and such accumulation suggests that Ag may be transferred to higher trophic levels when plants are exposed to Ag-GO in ecosystems. Our study can, thus, serve as an important basis for setting guidelines for the release of nanomaterials into the environment. 


\section{Effects of silver-graphene oxide on seed germination 2 and early growth of crop species}

3

4

5

6

7

8 9

22

23

24

25

26

27

28

29

30

31

32

33

34

35

36

37

38

39

40

41
Min-Ji Kim¹, Woong Kim ${ }^{1}$, Haegeun Chung ${ }^{2 *}$

${ }^{1}$ Department of Materials Science and Engineering, Korea University, Seoul 02473, Republic of Korea

${ }^{2}$ Department of Environmental Engineering, Konkuk University, Seoul, 05029, Republic of Korea

Corresponding Author:

Haegeun Chung ${ }^{2}$

Konkuk University, 120, Neungdong-ro, Gwangjin-gu, Seoul, 05029, Republic of Korea Email address: hchung@konkuk.ac.kr 


\section{Abstract}

43 Due to its excellent material properties, silver-graphene oxide (Ag-GO) is being studied for

44

45

46

47

48

49

50

51

52

53

54

55

56

57

58

59

60

61

62

63

64

65

66

67

68

69

70

71

72

73

74

75

76

77

78

79

80

81 diverse applications, such as antimicrobial agents, catalysts, and absorbents. Such use of Ag-GO may lead to its release into terrestrial ecosystems, but little is known about the impact of Ag-GO on plants. In the present study, we determined the effects of Ag-GO on seed germination and early growth of crop species by analyzing the germination rate, growth of roots and shoots, hydrogen peroxide $\left(\mathrm{H}_{2} \mathrm{O}_{2}\right)$ accumulation, and the uptake of $\mathrm{Ag}$ in alfalfa, radish, and cucumber treated with 0.2 to $1.6 \mathrm{mg} \mathrm{mL}^{-1}$ of Ag-GO. Ag-GO treatment increased the shoot growth of radish at 0.2 to $1.6 \mathrm{mg} \mathrm{mL}^{-1}$ but decreased that of cucumber at $0.8 \mathrm{mg} \mathrm{mL}^{-1}$. In addition, Ag-GO enhanced the root elongation of radish at $0.2 \mathrm{mg} \mathrm{mL}^{-1}$ but inhibited that of alfalfa at $0.2,0.8$, and $1.6 \mathrm{mg} \mathrm{mL}{ }^{-1}$. Ag-GO treatment induced $\mathrm{H}_{2} \mathrm{O}_{2}$ production in alfalfa, radish, and cucumber in a concentration-dependent manner. Larger amounts of Ag accumulated in the seedlings as the concentration of Ag-GO increased, and such accumulation suggests that Ag may be transferred to higher trophic levels when plants are exposed to Ag-GO in ecosystems. Our study can, thus, serve as an important basis for setting guidelines for the release of nanomaterials into the environment.

\section{Introduction}

With the rapid progress of nanotechnology in recent years, nanomaterials are being used in many products, including cosmetics, agrochemicals, and biochemical sensors (Alivisatos, 2004; Nair et al., 2010; Fleming and Ulijn, 2014; Yang et al., 2019). One of the most widely used nanomaterials for commercial products is silver nanoparticle (Ag NP), owing to their superb material characteristics, including a high antibacterial activity and unique surface plasmon resonance (Ahamed, Mohamad \& Siddiqui, 2010; Vance et al., 2015). However, Ag NPs can be easily aggregated; therefore, nanocomposites have been formed with carbon materials such as graphene oxide $(\mathrm{GO})$ and photocatalytic materials as supporting materials to maintain the stability of Ag NPs. As the result of the oxidation of graphite, GO with $\mathrm{sp}^{2}$-bonded carbon atoms has many oxygen functional groups, allowing Ag NPs to be formed easily on a sheet of GO. The formation of Ag NPs on a GO sheet not only prevents the agglomeration of Ag NPs, but also enhances their material properties, such as their antibacterial activity and electronic and magnetic properties (Xu et al., 2011; Li et al., 2013). Due to its excellent properties, Ag-GO is increasingly being studied for many applications, e.g., as an antibacterial agent for water disinfection, application on membranes for antifouling, catalysts, and electrochemical biosensors (Bao, Zhang \& Qi, 2011; Ko et al., 2018; Naeem et al., 2019; Zhao et al., 2019). Thus, the potential of Ag-GO for application in diverse fields warrants investigation into its environmental impacts.

In addition to the abovementioned applications, Ag-GO with high antimicrobial activity has been investigated as a novel antimicrobial agent for the control of crop diseases (Ocsoy et al., 2013; Chen et al., 2016; Liang, Yang \& Cui, 2017). Ag-GO has been shown to have a higher antibacterial activity against Xanthomonas perforans, a tomato bacterial spot pathogen, than GO 
82 or Ag NPs alone. Ag-GO deformed the bacterial structure and destroyed the cell membrane by 83 wrapping the $X$. perforans cell, while exerting no phytotoxicity against tomato leaves (Ocsoy et 84 al., 2013). Similarly, $2.5 \mu \mathrm{g} \mathrm{mL}{ }^{-1}$ of Ag-GO had antibacterial activity against bacterial leaf blight 85 of rice caused by Xanthomonas oryzae pv. oryzae (Xoo). Ag-GO damaged the structure of the 86 Xoo cell wall and membrane, and caused leakage of the cell contents (Liang, Yang \& Cui, 2017). 87 In addition, Ag-GO deformed the structure of hyphae and induced reactive oxygen species 88 (ROS) in Fusarium graminearum, which cause leaf spot disease (Chen et al., 2016). Hence, the 89 antimicrobial activity of Ag-GO makes it a potential agent for controlling crop diseases. Given 90 the high potential for the application of Ag-GO in various fields, it is important to determine the 91 influence of Ag-GO on terrestrial ecosystems, especially on plants that play a central role in

Several studies have demonstrated the effects of Ag NPs on seed germination and plant growth (Barrena et al., 2009; El-Temsah and Joner, 2013; Rui et al., 2017; Yang et al., 2018). Treatment with $0.1 \mathrm{mg} \mathrm{mL}^{-1}$ of Ag NPs inhibited the root elongation of cucumber by $15 \%$, but it had no significant effect on the root elongation of lettuce (Barrena et al., 2009). In another study, treatment with Ag NPs that are $5 \mathrm{~nm}$ in diameter reduced the shoot length of flax and barley at $10 \mathrm{mg} \mathrm{L}^{-1}$, and that of ryegrass at 10,20 , and $100 \mathrm{mg} \mathrm{L}^{-1}$. For Ag NPs that are $20 \mathrm{~nm}$ in diameter, the shoot growth of all three plants was inhibited at $20 \mathrm{mg} \mathrm{L}^{-1}$; thus, the inhibitory effect of $\mathrm{Ag}$ NPs was not size-dependent (El-Temsah and Joner, 2013). In addition, inhibited growth was observed in wheat and peanuts grown in soils amended with Ag NPs (Rui et al., 2017; Yang et al., 2018).

Other reports have shown both positive and negative effects of graphene on plants (Begum, Ikhtiari \& Fugetsu, 2011; Zhang et al., 2015; Jiao et al., 2016). Treatment with $2 \mathrm{mg} \mathrm{mL}^{-1}$ of graphene for 20 days significantly reduced the growth and biomass of cabbage, red spinach, and tomato seedlings. Furthermore, graphene caused oxidative stress and membrane leakage in these species. However, lettuce treated at this dosage of graphene showed no significant difference in plant growth or $\mathrm{H}_{2} \mathrm{O}_{2}$ production (Begum, Ikhtiari \& Fugetsu, 2011). In contrast, another study demonstrated that graphene at $40 \mu \mathrm{g} \mathrm{mL}-1$ positively affected seed germination and seedling growth of tomato. More specifically, treatment with graphene increased the stem and root lengths and total fresh weight of tomato seedlings because graphene could penetrate seed husks, resulting in the facilitation of water uptake (Zhang et al., 2015). In another study, treatment with $20 \mathrm{mg} \mathrm{L}^{-1} \mathrm{GO}$ decreased the root length of tobacco compared with that of the control on day 20 , but it enhanced the root length of tobacco by two to three times more than that of the control after 35 days. Moreover, GO increased the activity of peroxidase (POD), superoxide dismutase (SOD), and catalase (CAT) and decreased the malondialdehyde (MDA) content in tobacco seedlings (Jiao et al., 2016). 
121 Despite the reports on the effects of Ag NPs and GO on various plant species, few studies have

122 been conducted to investigate the impact of Ag-GO on plants. In the present study, we

123 determined the effects of Ag-GO on seed germination and early growth of three plant species,

124 alfalfa, radish, and cucumber. Alfalfa, used as fodder, plays an important role in agricultural

125 ecosystems by fixing nitrogen. Radish and cucumber are vegetable crops that have been

126 previously used to investigate the effects of nanomaterials (Wierzbicka and Obidzińska, 1998;

127 Migliore, Cozzolino \& Fiori, 2003). We examined changes in the germination rate and shoot and

128 root lengths to investigate the potential effects of Ag-GO on germination and seedling growth

129 and measured the $\mathrm{H}_{2} \mathrm{O}_{2}$ content to confirm the oxidative stress due to ROS. In addition, the $\mathrm{Ag}$

130 content in the seedlings of the three species was measured to determine the uptake of Ag upon

131 Ag-GO treatment.

132

\section{Materials \& Methods}

\section{Synthesis and characterization of Ag-GO}

GO was prepared using a modification of Hummers' method described elsewhere (Hummers and Offeman, 1958; Chung et al., 2015), and Ag-GO was synthesized by the glucose reduction method (Tang et al., 2013; Kim et al., 2018). Briefly, $50 \mathrm{~mL}$ of an aqueous GO solution (0.5 mg $\mathrm{mL}^{-1}$ ) was ultrasonicated for $1 \mathrm{~h}$ using a bar sonicator (VC 750 ultrasonic processor, Sonic \& Materials Inc., USA). The GO solution was mixed uniformly with $10 \mathrm{~mL}$ polyvinylpyrrolidone (PVP) solution (4 mg mL-1, average molecular weight 29,000 , Sigma-Aldrich) and $800 \mathrm{mg}$ glucose (Sigma-Aldrich), and the solution was heated at $45^{\circ} \mathrm{C}$. Subsequently, silver-ammonium hydroxide solution $(10 \mathrm{~mL})$ was added and the solution was held at $45^{\circ} \mathrm{C}$ for $7 \mathrm{~min}$. The mixture was centrifuged at $12,298 \times g$ for $10 \mathrm{~min}$ and the supernatant was decanted; the remaining pellet was washed several times with deionized (DI) water to remove excess ions and dried at $80{ }^{\circ} \mathrm{C}$.

The microscopic morphology of Ag-GO was observed by transmission electron microscopy (Tecnai 20, FEI, USA). Absorption spectra were recorded using a UV-VIS spectrophotometer (Varian Cary 50, Cary, USA). Raman spectroscopy was conducted using a LabRAM ARAMIS IR2 (Horiba, Japan) to analyze the defects and strain in Ag-GO and GO. X-ray photoelectron spectroscopy (XPS) spectra were measured with an automated XPS Microprobe (PHI 5000 Versa Probe, ULVAC-PHI, Japan) to compare the surface bonding before and after deposition of Ag NPs on the GO sheet; the ratio of Ag to GO was calculated through XPS.

\section{Seed exposure}

Three plant species, alfalfa (Medicago sativa L.), radish (Raphanus sativus. L.), and cucumber (Cucumis sativus L.), were used in our study, and the seeds of these plants which were stored after harvest were purchased from Danong Inc. Korea. Before exposure to the nanomaterials, seeds were soaked in a $10 \%$ sodium hypochlorite solution for $10 \mathrm{~min}$ to sterilize them and rinsed with DI water three times (US Environmental Protection Agency, 2012). Ten sterilized seeds were transferred onto filter paper placed in a $100 \times 15 \mathrm{~mm}$ Petri dish containing $5 \mathrm{~mL}$ of Ag-GO 
161

162

163

164

165

166

167

168

169

170

171

172

173

174

175

176

177

178

179

180

181

182

183

184

185

186

187

188

189

190

191

192

193

194

195

196

197

198

199

200

suspension at different concentrations $\left(0,0.2,0.4,0.8\right.$, and $\left.1.6 \mathrm{mg} \mathrm{mL}^{-1}\right)$. The different concentrations were prepared by diluting the stock Ag-GO suspension of $1.6 \mathrm{mg} \mathrm{mL} \mathrm{m}^{-1}$. Additionally, $1.6 \mathrm{mg} \mathrm{mL}^{-1}$ of GO and Ag NPs were applied to seeds to compare their effects to those of Ag-GO. Ag NPs (Sigma-Aldrich) were stabilized using polyvinylpyrrolidone (PVP) and their diameter was 70.2 $\pm 4.9 \mathrm{~nm}$ (Yasur and Rani, 2013). Petri dishes were sealed with parafilm and incubated at $25^{\circ} \mathrm{C}$ in the dark for seven days. Four replicates of each treatment were analyzed, for a total of 40 seeds per test species. During incubation, the germination percentage was determined every two days by counting the number of germinated seeds that had roots longer than $2 \mathrm{~mm}$; the shoot and root lengths were measured at the end of the incubation period using a ruler.

\section{Analysis of $\mathrm{H}_{2} \mathrm{O}_{2}$ in seedlings}

The Amplex ${ }^{\circledR}$ red hydrogen peroxide/peroxidase assay kit (Invitrogen ${ }^{\mathrm{TM}}$, USA) was used for the determination of $\mathrm{H}_{2} \mathrm{O}_{2}$ on day 7 at the end of the experiment. Seedlings were washed with DI water to remove nanomaterials on the surface of the seedlings. Adhering moisture was removed from the seedlings before grinding them in liquid nitrogen using a mortar and pestle. Fifty milligrams of tissue powder were resuspended in $250 \mu \mathrm{L}$ of cold phosphate buffer $(20 \mathrm{mM}$ $\left.\mathrm{K}_{2} \mathrm{HPO}_{4}, \mathrm{pH} 6.5\right)$. After centrifugation at $4{ }^{\circ} \mathrm{C}, 50 \mu \mathrm{L}$ of supernatant was incubated with $0.2 \mathrm{U}$ $\mathrm{mL}^{-1}$ horseradish peroxidase and $100 \mu \mathrm{M}$ Amplex red reagent (10-acetyl-3,7dihydrophenoxazine) at room temperature in the dark for $30 \mathrm{~min}$. Subsequently, the fluorescence was measured with a Synergy HT multi-mode microplate reader (Biotek, USA) (excitation at $530 \mathrm{~nm}$ and emission at $590 \mathrm{~nm}$ ).

\section{Quantification of silver content in fresh seedlings}

Ag content in seedlings was quantified on day 7, at the end of the experiment, following the method described by Geisler-Lee et al. (2012) with modifications. Seedlings of the three species were washed with DI water and their fresh weight was measured. Seedlings were fully digested using a mixture of $2 \mathrm{~mL}$ of $\mathrm{HNO}_{3}$ used for trace-metal analysis (70\%, Sigma-Aldrich) and $1 \mathrm{~mL}$ Co standard solution (1000 mg mL $\mathrm{m}^{-1}$ in nitric acid, Sigma-Aldrich) heated at $120{ }^{\circ} \mathrm{C}$ for $30 \mathrm{~min}$. After the solution cooled down, $2 \mathrm{~mL}$ of $\mathrm{H}_{2} \mathrm{O}_{2}$ used for trace analysis $\left(\mathrm{H}_{2} \mathrm{O}_{2}, \sim 30 \% \mathrm{w} / \mathrm{w}\right.$, SigmaAldrich) was added and the mixture was heated at $120^{\circ} \mathrm{C}$ for $30 \mathrm{~min}$. The digested samples were diluted with DI water to $20 \mathrm{~mL}$ and filtered using a $0.22-\mu \mathrm{m}$ polyvinylidene fluoride (PVDF) syringe filter. Each diluted sample was analyzed using an inductively coupled plasma-optical emission spectrometer (ICP-OES, iCAP6300 Duo, Thermo Scientific, USA).

\section{Statistical analyses}

Statistical analyses were carried out using SAS ${ }^{\circledR}$ version 9.4 (SAS Inc., USA) to test the effects of Ag-GO, Ag, and GO on seed germination. One-way analyses of variance (ANOVA) were employed to determine the effect of Ag-GO treatment on germination percentage, the lengths of the root and shoot, $\mathrm{H}_{2} \mathrm{O}_{2}$ content, and $\mathrm{Ag}$ content in seedlings. Additionally, one-way ANOVA 
201

202

203

204

205

206

207

208

209

210

211

212

213

214

215

216

217

218

219

220

221

222

223

224

225

226

227

228

229

230

231

232

233

234

235

236

237

238

239

240

was conducted to compare the effects of treatments with Ag-GO, Ag NPs, and GO at a concentration of $1.6 \mathrm{mg} \mathrm{mL}^{-1}$. The effects of the treatments were accepted as significant at $\alpha=$ 0.05. Tukey's honestly significant difference test was conducted to further investigate which means differed from other means within a group $(p<0.05)$ when the effect of each treatment was significant for the parameters studied. In addition, regression analyses were performed to determine the relationship between the concentration of Ag-GO treatment and Ag content in seedlings treated with Ag-GO.

\section{Results}

\section{Characterization of Ag-GO}

The TEM images of Ag-GO showed that the Ag NPs were formed on the wrinkled surface of GO (Figure 1A, B). The average diameter of Ag NPs was $57.5 \pm 1.9$ (average \pm one standard error; $n=250$ ) $\mathrm{nm}$. The UV-VIS spectrum of GO (Figure 1C) displayed no obvious absorption band in the wavelength range of 300 to $800 \mathrm{~nm}$. In contrast, the UV-VIS spectrum of Ag-GO showed maximum absorbance at $430 \mathrm{~nm}$, indicating that Ag NPs were loaded on the GO sheets. The Raman spectra of Ag-GO and GO (Figure 1D) showed two peaks, the D band at $1350 \mathrm{~cm}^{-1}$ and the $\mathrm{G}$ band at $1590 \mathrm{~cm}^{-1}$. However, the intensity of the $\mathrm{D}$ and $\mathrm{G}$ bands in the Raman spectrum of Ag-GO was enhanced by surface-enhanced Raman scattering. The $I_{D} / I_{G}$ ratios of GO and Ag-GO are 0.95 and 0.92, respectively. Analysis of surface bonding using XPS (Figure 1E, F) clearly showed that the intensity of oxygenated carbon bonds decreased after Ag NP formation on GO. The XPS C1s spectra of GO showed three main peaks, for $\mathrm{C}-\mathrm{C}, \mathrm{C}-\mathrm{O}$, and $\mathrm{C}=\mathrm{O}$ bonds. The $\mathrm{C}-\mathrm{O}$ and $\mathrm{C}=\mathrm{O}$ bond peaks of $\mathrm{Ag}-\mathrm{GO}$ showed a relatively lower intensity than those of GO. Additionally, the carbon-to-oxygen ratio increased from 2.0 to 4.1 after Ag NP formation on the GO sheet. The reduction of oxygenated carbon after Ag NP formation on a GO sheet has also been demonstrated by other groups (Tang et al., 2013; Kim et al., 2018). The weight ratio of $\mathrm{Ag}$ to $\mathrm{GO}$ was approximately 0.64 .

\section{Effects of Ag-GO on seed germination and seedling growth}

Treatment with Ag-GO had no significant effect on germination percentage (Table 1). In addition, germination percentage was not altered by Ag NP or GO treatment. Regardless of the Ag-GO treatment concentration, $100 \%$ of the alfalfa and cucumber seeds germinated on day 4 and day 7, respectively, and $95-100 \%$ of radish seeds germinated on day 7. Ag-GO had both positive and negative effects on seedling growth (Figure 2). The shoot length of alfalfa was not affected significantly by Ag-GO treatment; however, that of radish and cucumber showed a significant response to treatment with Ag-GO (Figure 2A). More specifically, the shoot length of radish treated with $\mathrm{Ag}-\mathrm{GO}$ at 0.2 to $1.6 \mathrm{mg} \mathrm{mL}^{-1}$ increased up to $52 \%(p<0.0001)$ and that of radish treated with Ag NPs at $1.6 \mathrm{mg} \mathrm{mL}^{-1}$ increased by $36 \%$ when compared to the control. However, the shoot length of cucumber decreased by $16 \%$ upon treatment with Ag-GO at $0.8 \mathrm{mg}$ $\mathrm{mL}^{-1}$ compared to the control $(p=0.0003)$. 
241 Ag-GO treatment also had a significant effect on the root growth of alfalfa and radish (Figure

242 2B). Treatment with $1.6 \mathrm{mg} \mathrm{mL}^{-1}$ of Ag-GO inhibited the root elongation of alfalfa by $41 \%$

243 compared to that of the control $(p=0.0011)$. However, the root length of radish treated with 0.2

$244 \mathrm{mg} \mathrm{mL}^{-1}$ of Ag-GO increased by $45 \%$ compared to that of the control $(p=0.0456)$ and its effect

245 on root elongation significantly differed from that of $1.6 \mathrm{mg} \mathrm{mL}^{-1}$ of GO $(p=0.0002)$. In

246 contrast, treatment with Ag-GO had no significant effect on the root length of cucumber.

247 Overall, the effects of Ag-GO, Ag NPs, and GO treatments on root elongation differed

248 significantly $(p<0.001)$.

249

250

\section{$\mathrm{H}_{2} \mathrm{O}_{2}$ content in seedlings treated with Ag-GO}

251

252

Ag-GO treatment significantly increased the $\mathrm{H}_{2} \mathrm{O}_{2}$ content in alfalfa and radish seedlings (Figure

253

3). When alfalfa was treated with $1.6 \mathrm{mg} \mathrm{mL}^{-1}$ of Ag-GO, its $\mathrm{H}_{2} \mathrm{O}_{2}$ content was more than twice that of the control $(p<0.0001)$ and similar to that in alfalfa treated with $1.6 \mathrm{mg} \mathrm{mL}^{-1}$ of Ag NPs

254 $(p<0.0001)$. In radish, the production of $\mathrm{H}_{2} \mathrm{O}_{2}$ was increased by treatment with $\mathrm{Ag}-\mathrm{GO}$

255

256

257

258

259

260

261

262

263

264

265

266

267

268

269

270

271

272

273

274

275

276

277

278

279

280 compared to that in the control $(p<0.0001)$. In addition, the level of $\mathrm{H}_{2} \mathrm{O}_{2}$ significantly differed for Ag-GO, Ag NPs, and GO treatments $(p<0.0001)$. In contrast, the content of $\mathrm{H}_{2} \mathrm{O}_{2}$ in cucumber seedlings was not altered by Ag-GO, Ag NPs, or GO treatments.

\section{Ag content of seedlings treated with Ag-GO}

The results of the regression analysis showed that the concentration of Ag-GO and the Ag content in the three seedlings were positively correlated. For example, the Ag content in alfalfa was positively correlated with the treatment concentration of Ag-GO $\left(p<0.001, R^{2}=0.85\right)$. Likewise, in the case of radish and cucumber, there was positive correlation between the concentration of Ag-GO and Ag content in these species $\left(p=0.004, R^{2}=0.71\right.$ in radish and $p<$ $0.0001, R^{2}=0.94$ in cucumber). According to the ANOVA results, there were no significant differences in the $\mathrm{Ag}$ content in alfalfa and radish at the concentrations of $0.2,0.4$, and $0.8 \mathrm{mg}$ $\mathrm{mL}^{-1}$ of Ag-GO. However, at $1.6 \mathrm{mg} \mathrm{mL}^{-1}$ of Ag-GO, Ag accumulation in alfalfa and radish was significantly higher than that for the other treatments $(p<0.0001$ and $p=0.0059$, respectively). In cucumber, there was no significant difference in $\mathrm{Ag}$ content between 0.2 and $0.4 \mathrm{mg} \mathrm{mL}^{-1}$ of Ag-GO treatments, but the Ag content was significantly higher at 0.8 and $1.6 \mathrm{mg} \mathrm{mL}^{-1}$ of $\mathrm{Ag-GO}$ $(p<0.001)$ (Figure 4). The Ag contents in alfalfa and radish treated with $1.6 \mathrm{mg} \mathrm{mL}^{-1}$ of Ag-GO were $93.9 \pm 11.6 \mathrm{ng} \mathrm{mg}^{-1}$ fresh weight (F.W.), and $43.6 \pm 2.0 \mathrm{ng} \mathrm{mg}^{-1}$ F.W., respectively. The Ag content in cucumber treated with $1.6 \mathrm{mg} \mathrm{mL}^{-1}$ of Ag-GO was $12.5 \pm 1.5 \mathrm{ng} \mathrm{mg}^{-1} \mathrm{~F}$.W., which was four times the content of $\mathrm{Ag}$ in cucumber treated with $0.2 \mathrm{mg} \mathrm{mL}^{-1}$ of Ag-GO. Furthermore, the Ag content for Ag-GO and Ag NP treatments was significantly different in alfalfa and radish. The Ag content in alfalfa and radish exposed to $1.6 \mathrm{mg} \mathrm{mL}^{-1}$ of Ag-GO was approximately two times that of seedlings treated with $1.6 \mathrm{mg} \mathrm{mL}^{-1}$ of Ag NPs $(p<0.0049$ and $p=0.0079$, respectively). However, the Ag content in cucumber was similar for both treatments (Figure 4).

\section{Discussion}


281 The effects of Ag-GO on the early growth of plants were dependent on the plant species with 282 different seed size. The three species used in the present study are from different plant families 283 and have seeds of different sizes, and they showed distinct responses to Ag-GO. Root elongation 284 of the small-seeded alfalfa and radish were enhanced and inhibited, respectively, by Ag-GO 285 treatment, but that of the large-seeded cucumber was not affected. Similarly, in studies that have 286 determined the effects of multi-walled carbon nanotubes, the germination of small-seeded

287

288

289

290

291

292

293

294

295

296

297

298

299

300

301

302

303

304

305

306

307

308

309

310

311

312

313

314

315

316

317

318

319

320 species such as lettuce were affected whereas large-seeded species such as cucumber were not affected by multi-walled carbon nanotube treatment. Therefore, the difference in seed size might be a factor that accounts for the difference in the response of plants to nanomaterials (Cañas et al., 2008; Begum et al., 2012). Additionally, according to previous studies, the effects of nanomaterials on plants depend on the characteristics of the nanomaterials and the xylem anatomy of the plants, which affect the absorption of the nanomaterials onto the root (Cañas et al., 2008; Begum, Ikhtiari \& Fugetsu, 2011). Begum, Ikhtiari \& Fugetsu (2011) showed that the response of cabbage, tomato, red spinach, and lettuce to graphene depends on the plant species, because of differences in root systems. High concentrations of graphene inhibited the growth of cabbage, tomato, and red spinach, but had no significant effect on lettuce. These results are likely due to the difference in the uptake of nanomaterials by distinctive xylem structures. Likewise, Cañas et al. (2008) reported that the response of plants to nanomaterials varies among plant species and that it depends on the characteristics of nanomaterials.

In our study, treatment with $\mathrm{Ag}-\mathrm{GO}$ and $\mathrm{Ag}$ NPs increased the length of shoots and roots in radish but had no effect on root length in cucumber. However, in another study, radish and cucumber treated with Ag NPs showed different responses compared to our results, owing to the properties of the nanomaterials used. More specifically, Ag NPs with a size in the range of 1 to $10 \mathrm{~nm}$ decreased elongation of the shoot and root when applied at a concentration of $0.5 \mathrm{mg} \mathrm{mL}^{-1}$ (Zuverza-Mena et al., 2016). Altogether, the responses of the plants vary depending on the characteristics of the nanomaterials, such as the particle size.

Treatment with Ag-GO led to the production of $\mathrm{H}_{2} \mathrm{O}_{2}$ during early seedling growth, but relatively low levels of $\mathrm{H}_{2} \mathrm{O}_{2}$ may enhance seedling growth. Plants produce several kinds of ROS as byproducts of aerobic metabolic pathways, and excessive ROS can cause oxidative damage to proteins, DNA, lipids, and finally cell death (Apel and Hirt, 2004). Several studies demonstrated that nanomaterials produced $\mathrm{H}_{2} \mathrm{O}_{2}$ and induced oxidative stress in plants (Begum, Ikhtiari \& Fugetsu, 2011; Anjum et al., 2013). Begum, Ikhtiari \& Fugetsu (2011) showed that graphene induced dose-dependent $\mathrm{H}_{2} \mathrm{O}_{2}$ accumulation in cabbage, tomato, and red spinach at concentrations of 500, 1000, and $2000 \mathrm{mg} \mathrm{L}^{-1}$ using the ROS-sensitive probe $2^{\prime}, 7^{\prime}-$ dichlorofluorescein diacetate (DCFH-DA). It induced oxidative stress by causing cell membrane damage and electrolyte leakage in leaves. According to our results, high concentrations of $\mathrm{H}_{2} \mathrm{O}_{2}$ in alfalfa induced by Ag-GO likely inhibited root growth. However, the relatively low levels of $\mathrm{H}_{2} \mathrm{O}_{2}$ in radish and cucumber weakly affected the seedling growth. In a previous study, Anjum et 
321 al. (2013) demonstrated that the activity of catalase and ascorbate peroxidase in faba bean (Vicia

322

323

324

325

326

327

328

329

330

331

332

333

334

335

336

337

338

339

340

341

342

343

344

345

346

347

348

349

350

351

352

353

354

355

356

357

358

359

faba L.) seedlings was increased by treatment with 400 and $800 \mathrm{mg} \mathrm{L}^{-1}$ of graphene, and this prevents the overproduction of $\mathrm{H}_{2} \mathrm{O}_{2}$ in faba bean seedlings. Consequently, the low level of $\mathrm{H}_{2} \mathrm{O}_{2}$ accumulated in faba bean seedlings could increase the absorption of liquid by seeds, enhancing the emergence and length of the root.

Seedlings treated with Ag-GO accumulated more Ag at higher concentrations of Ag-GO. Previous studies have also demonstrated that Ag uptake during seedling growth is dosedependent, but the amount of Ag uptake is different among plant species, treatment concentrations, and the physicochemical properties of Ag NPs (Geisler-Lee et al., 2013; Zuverza-Mena et al., 2016). Geisler-Lee et al. (2013) demonstrated that in Arabidopsis thaliana, Ag NPs having a size of $40 \mathrm{~nm}$ translocated from border cells to internal root tissue and vascular tissue and that Ag accumulation was dose-dependent. Likewise, the Ag content in radish seedlings treated with 2-nm Ag NPs was concentration-dependent (Zuverza-Mena et al., 2016). This tendency was also observed in tomatoes and castor seeds treated with Ag NPs, but the accumulated amount differed according to several factors, such as the culture medium, seed size or coat, and physicochemical properties of the nanomaterials (Song et al., 2013; Yasur and Rani, 2013). Interestingly, the difference between Ag accumulation in seedlings treated with Ag-GO and those treated with Ag NPs was distinct for small-seeded species. Further study is needed to determine whether Ag accumulation is due to the $\mathrm{Ag}$ NPs on the GO sheet or due to $\mathrm{Ag}^{+}$and to investigate the interaction between $\mathrm{Ag}-\mathrm{GO}$ and the seedling surface.

\section{Conclusions}

We demonstrate here, that Ag-GO can significantly affect the early growth of plants in a speciesspecific manner. The shoot growth of cucumber and the root growth of alfalfa was inhibited by Ag-GO treatment, whereas the growth of roots and shoots in radish was enhanced by exposure to Ag-GO. The uptake of Ag from Ag-GO by seedlings was dose-dependent. The production of $\mathrm{H}_{2} \mathrm{O}_{2}$ increased with the concentration of Ag-GO, and high levels of $\mathrm{H}_{2} \mathrm{O}_{2}$ may account for the inhibited growth of alfalfa and cucumber seedlings. Further study to investigate other ROS and series of antioxidative mechanisms activated by Ag-GO and long-term experiments employing various plant species are necessary before Ag-GO can be utilized more widely in diverse fields.

\section{Acknowledgements}

\section{References}

Ahamed M, AlSalhi MS, Siddiqui MKJ. 2010. Silver nanoparticle applications and human health. Clinica Chimica Acta 411:1841-1848.

Alivisatos P. 2004. The use of nanocrystals in biological detection. Nature Biotechnology 22:4752.

Peer] reviewing PDF | (2019:07:39413:2:0:NEW 4 Dec 2019) 
360

361

362

363

364

365

366

367

368

369

370

371

372

373

374

375

376

377

378

379

380

381

382

383

384

385

386

387

388

389

390

391

392

393

394

395

396

397

398

399

Anjum NA, Singh N, Singh MK, Sayeed I, Duarte AC, Pereira E, Ahmad I. 2014. Single-bilayer graphene oxide sheet impacts and underlying potential mechanism assessment in germinating faba bean (Vicia faba L.). Science of Total Environment 472:834-841.

Apel K, Hirt H. 2014. Reactive oxygen species: metabolism, oxidative stress, and signal transduction. Annual Reviews of Plant Biology 255:373-399.

Bao Q, Zhang D, Qi P. 2011. Synthesis and characterization of silver nanoparticle and graphene oxide nanosheet composites as a bactericidal agent for water disinfection. Journal of Colloid and Interface Science 360:463-470.

Barrena R, Casals E, Colón J, Font X, Sánchez A, Punts V. 2009. Evaluation of the ecotoxicity of model nanoparticles. Chemosphere 75:850-857.

Begum P, Ikhtiari R, Fugetsu B. 2011. Graphene phytotoxicity in the seedling stage of cabbage, tomato, red spinach, and lettuce. Carbon 49:3907-3919.

Begum P, Ikhtiari R, Fugetsu B, Matsuoka M, Akasaka T, Watari F. 2012. Phytotoxicity of multi-walled carbon nanotubes assessed by selected plant species in the seedling stage. Applied Surface Science 262, 120-124.

Cañas JE, Long M, Nations S, Vadan R, Dai L, Luo M, Ambikapathi R, Lee EH, Olszyk D. 2008. Effects of functionalized and nonfunctionalized single-walled carbon nanotubes on root elongation of select crop species. Environmental Toxicology and Chemistry 27:1922-1931.

Chen J, Sun L, Cheng Y, Lu Z, Shao K, Li T, Hu C, Han H. 2016. Graphene oxide-silver nanocomposite: novel agricultural antifungal agent against Fusarium graminearum for crop disease prevention. ACS Applied Materials Interfaces 8:24057-24070.

Chung H, Kim MJ, Ko K, Kim JH, Kwon HA, Hong I, Park N, Lee S, Kim W. 2015. Effects of graphene oxides on soil enzyme activity and microbial biomass. Science of Total Environment 514:307-313.

El-Temsah YS, Joner EJ. 2012. Impact of Fe and Ag nanoparticles on seed germination and differences in bioavailability during exposure in aqueous suspension and soil. Environmental Toxicology 27:42-49.

Fleming S, Ulijn RV. 2014. Design of nanostructures based on aromatic peptide amphiphiles. Chemical Society Reviews 43:8150-8177.

Geisler-Lee J, Wang Q, Yao Y, Zhang W, Geisler M, Li K, Huang Y, Chen Y, Kolmakov A, Ma X. 2013. Phytotoxicity, accumulation and transport of silver nanoparticles by Arabidopsis thaliana. Nanotoxicology 7:323-337.

Hummers Jr WS, Offeman RE. 1958. Preparation of graphitic oxide. Journal of American Chemistry Society 80:1339-1339.

Jiao J, Yuan C, Wang J, Xia Z, Xie L, Chen F, Li Z, Xu B. 2016. The role of graphene oxide on tobacco root growth and its preliminary mechanism. Journal of Nanoscience Nanotechnology 16:12449-12454.

Kim MJ, Ko D, Ko K, Kim D, Lee JY, Woo SM, Kim W, Chung H. 2018. Effects of silvergraphene oxide nanocomposites on soil microbial communities. Journal of Hazardous Materials 346:93-102. 
400 Ko K, Yu Y, Kim MJ, Kweon J, Chung H. 2018. Improvement in fouling resistance of silver401 graphene oxide coated polyvinylidene fluoride membrane prepared by pressurized filtration. 402 Separation and Purification Technology 194:161-169.

403 Li J, Kuang D, Feng Y, Zhang F, Xu Z, Liu M, Wang D. 2013. Green synthesis of silver 404 nanoparticles-graphene oxide nanocomposite and its application in electrochemical sensing of 405 tryptophan. Biosensors and Bioelectronics 42, 198-206.

406 Liang Y, Yang D, Cui J. 2017. A graphene oxide/silver nanoparticle composite as a novel 407 agricultural antibacterial agent against Xanthomonas oryzae pv. oryzae for crop disease 408 management. New Journal of Chemistry 41:13692-13699.

409 Migliore L, Cozzolino S, Fiori M. 2003. Phytotoxicity to and uptake of enrofloxacin in crop 410 plants. Chemosphere 52:1233-1244.

411 Naeem H, Ajmal M, Qureshi RB, Muntha ST, Farooq M, Siddiq M. 2019. Facile synthesis of 412 graphene oxide-silver nanocomposite for decontamination of water from multiple pollutants by 413 adsorption, catalysis and antibacterial activity. Journal of Environmental Management 230:199414211.

415 Nair R, Varghese SH, Nair BG, Maekawa T, Yoshida Y, Kumar DS. 2010. Nanoparticulate 416 material delivery to plants. Plant Science 179:154-163.

417 Ocsoy I, Paret ML, Ocsoy MA, Kunwar S, Chen T, You M, Tan W. 2013. Nanotechnology in 418 plant disease management: DNA-directed silver nanoparticles on graphene oxide as an 419 antibacterial against Xanthomonas perforans. ACS Nano 7:8972-8980.

420 Rui M, Ma C, Tang X, Yang J, Jiang F. Pan Y. Xiang Z, Hao Y, Rui Y, Cao W, Xing B. 2017. 421 Phytotoxicity of silver nanoparticles to peanut (Arachis hypogaea L.): physiological responses 422 and food safety. ACS Sustainable Chemistry and Engineering 5, 6557-6567.

423 Song B, Zhang C, Zeng G, Gong J, Chang Y, Jiang Y. 2016. Functional analyses of nanoparticle 424 toxicity: a comparative study of the effects of $\mathrm{TiO}_{2}$ and $\mathrm{Ag}$ on tomatoes (Lycopersicon 425 esculentum). Ecotoxicology and Environmental Safety 93:60-67.

426 Tang XZ, Li X, Cao Z, Yang J, Wang H, Pu X, Yu ZZ. 2013. Synthesis of graphene decorated 427 with silver nanoparticles by simultaneous reduction of graphene oxide and silver ions with 428 glucose. Carbon 59:93-99.

429 US Environmental Protection Agency. Ecological Effects Test Guidelines OCSPP 850.4150: 430 Vegetative Vigor. Office of Chemical Safety and Pollution Prevention. 2012; Washington, DC 431 Vance ME, Kuiken T, Vejerano EP, McGinnis SP, Hochella Jr, MF, Rejeski D, Hull MS. 2015. 432 Nanotechnology in the real world: Redeveloping the nanomaterial consumer products inventory. 433 Beilstein Journal of Nanotechnology 6:1769-1780.

434 Wierzbicka M, Obidzińska J. 1998. The effect of lead on seed imbibition and germination in 435 different plant species. Plant Science 137:155-171.

436 Xu WP, Zhang LC, Li JP, Lu Y, Li HH, Ma YN, Wang WD, Yu SH. 2011. Facile synthesis of 437 silver@graphene oxide nanocomposites and their enhanced antibacterial properties. Journal of 438 Materials Chemistry 21:4593-4597. 
439 Yang J, Jiang F, Ma C, Rui Y, Rui M, Adeel M, Cao W, Xing B. 2018. Alteration of crop yield

440 and quality of wheat upon exposure to silver nanoparticles in a life cycle study. Journal of

441 Agricultural and Food Chemistry 66: 2589-2597.

442 Yang K, Huang LJ, Wang YX, Du YC, Tang JG, Wang Y, Cheng MM, Zhang Y, Kipper MJ, 443 Belfiore LA, Wickramasinghe SR. 2019. Graphene oxide/nanometal composite membranes for 444 nanofiltration: synthesis, mass transport mechanism, and applications. New Journal of Chemistry 445 43:2846-2860.

446 Yasur J, Rani PU. 2013. Environmental effects of nanosilver: impact on castor seed germination, 447 seedlings growth, and plant physiology. Environmental Science and Pollution Research $448 \quad 20: 8636-8648$.

449 Zhang M, Gao B, Chen J, Li Y. 2015. Effects of graphene on seed germination and seedling 450 growth. Journal of Nanoparticle Research 17:1-8.

451 Zhao X, Li N, Jing M, Zhang Y, Wang W, Liu L, Xu Z, Liu L, Li F, Wu N. 2019.

452 Monodispersed and spherical silver nanoparticles/graphene nanocomposites from gamma-ray 453 assisted in-situ synthesis for nitrite electrochemical sensing. Electrochimica Acta 295:434-443. 454 Zuverza-Mena N, Armendariz R, Peralta-Videa JR, Gardea-Torresdey JL. 2016 Effects of silver 455 nanoparticles on radish sprouts: root growth reduction and modifications in the nutritional value. 456 Frontiers in Plant Science 7:90. 
Figure 1

Characterization of $\mathrm{Ag}-\mathrm{GO}$ and $\mathrm{GO}$.

(A, B) Transmission electron microscope (TEM) images of Ag-GO. (C) Ultraviolet-visible (UV-VIS) spectrum, (D) Raman spectrum, X-ray photoelectron spectroscope (XPS) C1s spectra and binding energy of (E) GO and (F) Ag-GO.
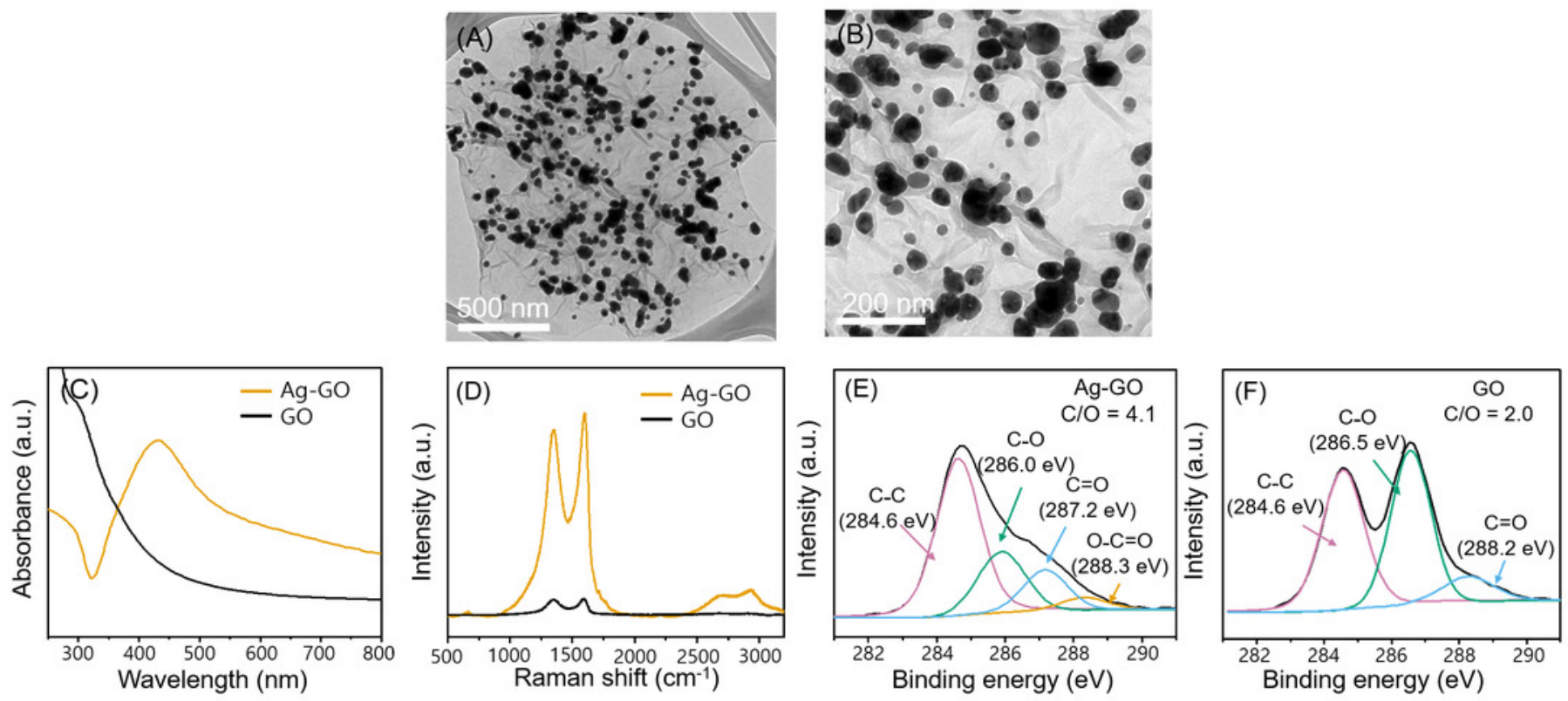


\section{Figure 2}

Effects of Ag-GO on the growth of alfalfa, radish, and cucumber seedlings. (A) Shoot length and (B) root length of seedlings at day 7 .

Means followed by the same letter are not significantly different at $\alpha=0.05$. Letters $a$ and $b$ indicate a significant difference among Ag-GO treatments at different concentrations, and $x$, $y$, and $z$ indicate that among $1.6 \mathrm{mg} \mathrm{mL}^{-1}$ of Ag-GO, Ag NP, and GO treatments. Error bars represent one standard error $(n=4)$. 

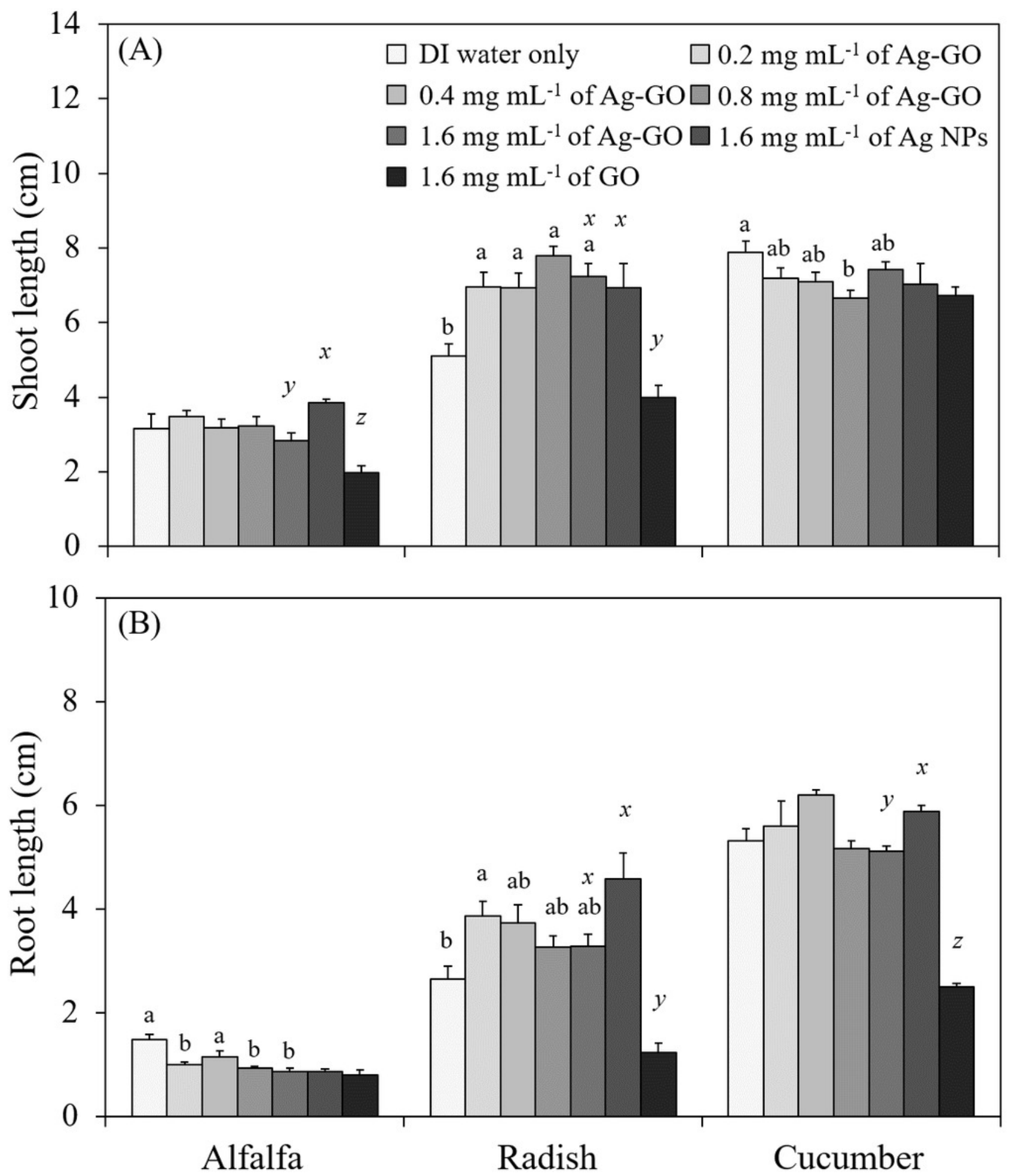


\section{Figure 3}

Effects of $\mathrm{Ag}-\mathrm{GO}$ on the accumulation of $\mathrm{H}_{2} \mathrm{O}_{2}$ in alfalfa, radish, and cucumber seedlings at day 7 .

Means followed by the same letter are not significantly different at $\alpha=0.05$. Letters $a, b$, and $c$ indicate a significant difference among Ag-GO treatments at different concentrations, and $x, y$, and $z$ indicate that among $1.6 \mathrm{mg} \mathrm{mL}^{-1}$ of Ag-GO, Ag NP, and GO treatments. Error bars represent one standard error $(n=4)$.

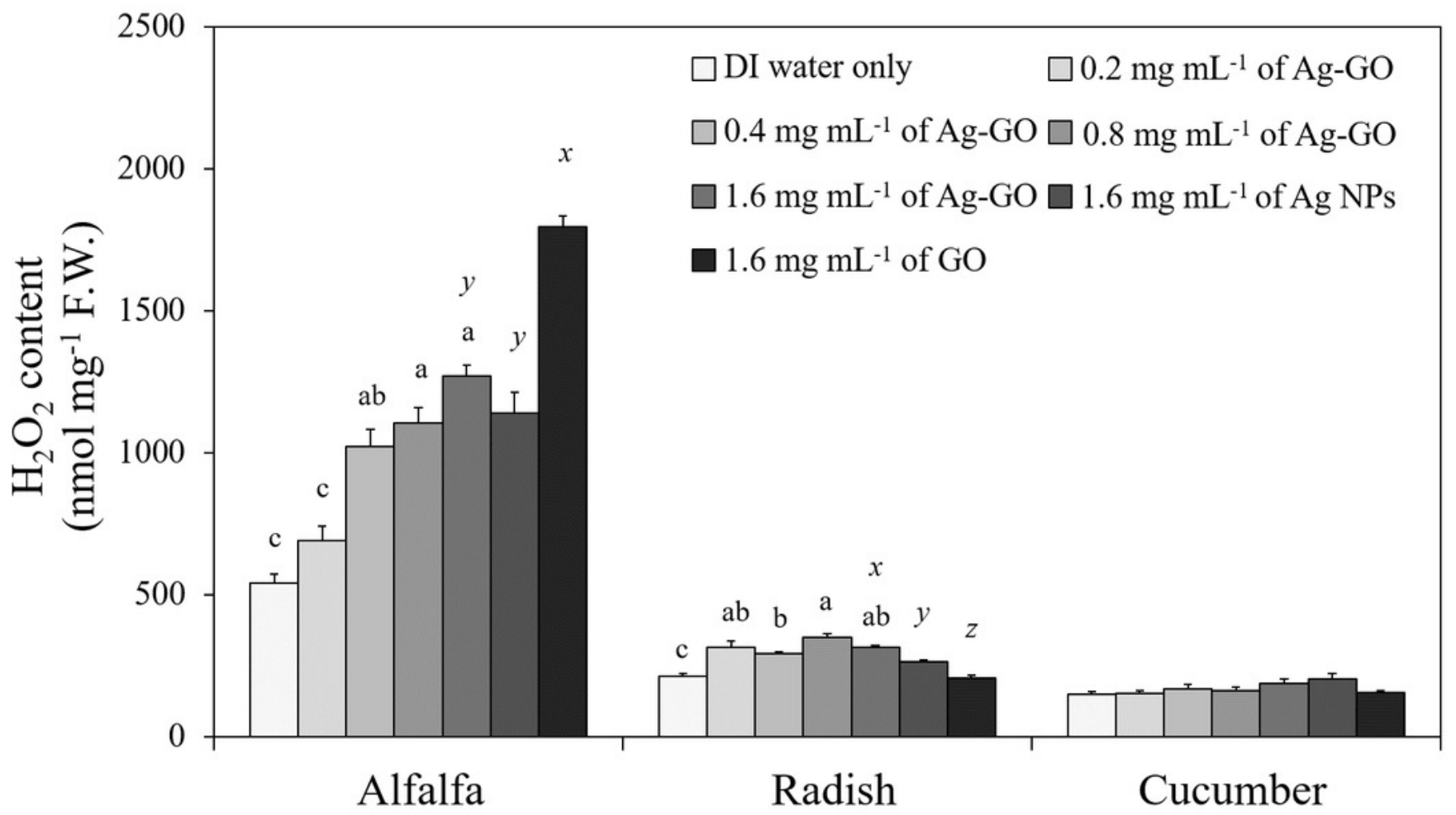


Figure 4

Concentration of $\mathrm{Ag}$ in seedlings exposed to $\mathrm{Ag}-\mathrm{GO}$ at $0.2,0.4,0.8$, and $1.6 \mathrm{mg} \mathrm{mL}^{-1}$ and Ag NPs at $1.6 \mathrm{mg} \mathrm{mL}^{-1}$ for seven days (average \pm one standard error, $n=4$ ).

The letters $a, b$, and $c$ denote a significant difference among Ag-GO treatments and $x$ and $y$ denote that between $1.6 \mathrm{mg} \mathrm{mL}^{-1}$ of Ag-GO and $1.6 \mathrm{mg} \mathrm{mL}^{-1}$ of Ag NP treatments.

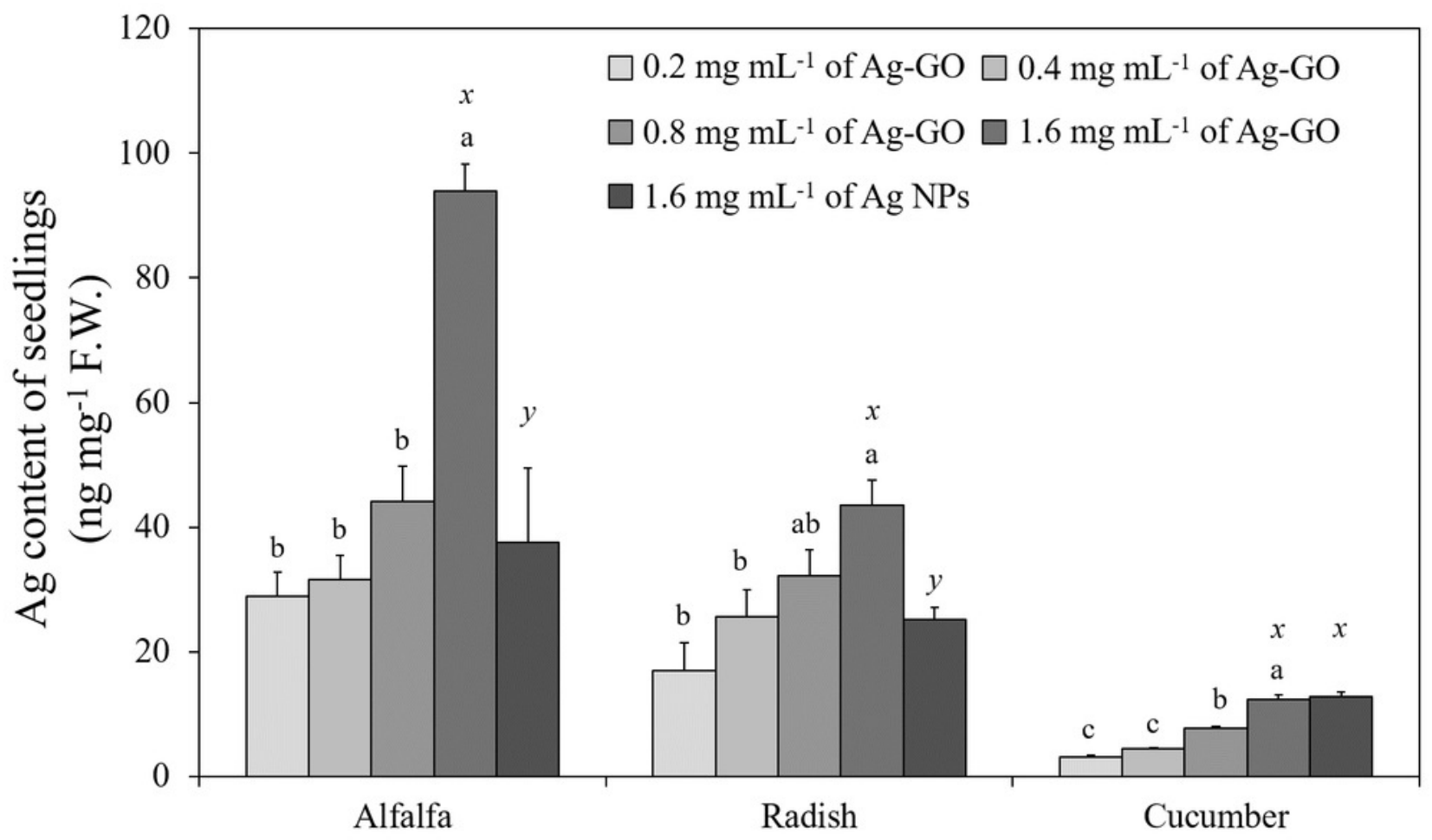




\section{Table $\mathbf{1}$ (on next page)}

Germination percentage (\%) of seedlings treated with Ag-GO, Ag NPs, and GO.

Germination percentage (\%) of seedlings treated with Ag-GO, Ag NPs, and GO (average \pm one standard error, $n=4$ ) 


\begin{tabular}{cccccccccc}
\hline & \multicolumn{3}{c}{ Alfalfa } & \multicolumn{3}{c}{ Radish } & \multicolumn{3}{c}{ Cucumber } \\
\cline { 2 - 9 } & Day 2 & Day 4 & Day 7 & Day 2 & Day 4 & Day 7 & Day 2 & Day 4 & Day 7 \\
\hline DI water only & 100 & 100 & 100 & $80 \pm 8$ & $93 \pm 5$ & 100 & 100 & 100 & 100 \\
$0.2 \mathrm{mg} / \mathrm{mL}$ of Ag-GO & $87 \pm 6$ & 100 & 100 & $89 \pm 4$ & $97 \pm 3$ & 100 & 100 & 100 & 100 \\
$0.4 \mathrm{mg} / \mathrm{mL}$ of Ag-GO & $72 \pm 12$ & 100 & 100 & $91 \pm 3$ & $95 \pm 4$ & $95 \pm 4$ & $96 \pm 2$ & 100 & 100 \\
$0.8 \mathrm{mg} / \mathrm{mL}$ of Ag-GO & $87 \pm 4$ & 100 & 100 & $73 \pm 6$ & $90 \pm 5$ & 100 & 100 & 100 & 100 \\
$1.6 \mathrm{mg} / \mathrm{mL}$ of Ag-GO & $90 \pm 4$ & 100 & 100 & $87 \pm 6$ & 100 & 100 & 100 & 100 & 100 \\
$1.6 \mathrm{mg} / \mathrm{mL}$ of Ag NPs & $90 \pm 4$ & 100 & 100 & $87 \pm 5$ & $97 \pm 3$ & 100 & 100 & 100 & 100 \\
$1.6 \mathrm{mg} / \mathrm{mL}$ of GO & 100 & 100 & 100 & 100 & 100 & 100 & 100 & 100 & 100 \\
\hline
\end{tabular}

1 